\title{
Long-term monitoring of slab deformation affected by the non-homogeneity of concrete
}

\author{
Sergej Priganc ${ }^{1}$, and Darina Kušnírová, ${ }^{1, *}$ \\ ${ }^{1}$ Institute of Structural Engineering, Faculty of Civil Engineering, Technical University of Košice, \\ 04200 Košice, Slovak Republic
}

\begin{abstract}
The shrinkage is a significant phenomenon in concrete structures. The article is aimed at monitoring the shrinking of concrete slabs under laboratory conditions. The results of laboratory research aimed at unreinforced slabs strains affected by the non-homogeneity of concrete are mentioned in the article. According to these results another research of shrinkage influence on strains and deflection of concrete slabs reinforced by steel, resp. GFRP reinforcement has been prepared. The results of this research confirm the significant effect of concrete non-homogeneity on the formation of strains and deflections due to shrinkage.
\end{abstract}

\section{Introduction}

In current regulations, the effects of concrete shrinking in the design and assessment of reinforced concrete structures are mainly considered in terms of their influence on the stress state of the crack limit calculation and the calculation of the deflection or axial shortening.

In general, concrete shrinking is defined as free or restrained. Free shrinking occurs if it is not prevented in any way. Restrained shrinking is affected by the reinforcement, respectively by bonds in statically indeterminable constructions. In the article we have focused on free shrinking on unreinforced concrete slabs and influence of non-homogeneity of concrete on shrinkage value. In the article, results from two similar but independent projects are presented and compared.

\section{Subject and methodology of the tests}

Both compared projects were focused on shrinkage influence on strains and stress of slabs reinforced on one side. As reference samples the unreinforced slabs were concreted on which the influence of non-homogeneity of concrete on shrinkage value was manifested. The tests for these projects had the same methodology but different conditions (relative humidity, temperature, concrete parameters and way of slabs reinforcing).

The unreinforced concrete slabs with nominal dimensions 1800x600x120 mm hung on stands in the vertical position (Fig. 1) were the subject of the tests. In such a position, the self-weight of the slab acts in the centre area. The high cross-section stands against the

\footnotetext{
* Corresponding author: darina.kusnirova@tuke.sk
} 
accrued bending moment and also due to the position of the hanging eyes, small stresses (in the order of $0.02 \mathrm{MPa}$ ) are formed in the sample. Therefore, when evaluating, it is possible to neglect the impact of self-weight, only the net effect of shrinkage is evident.
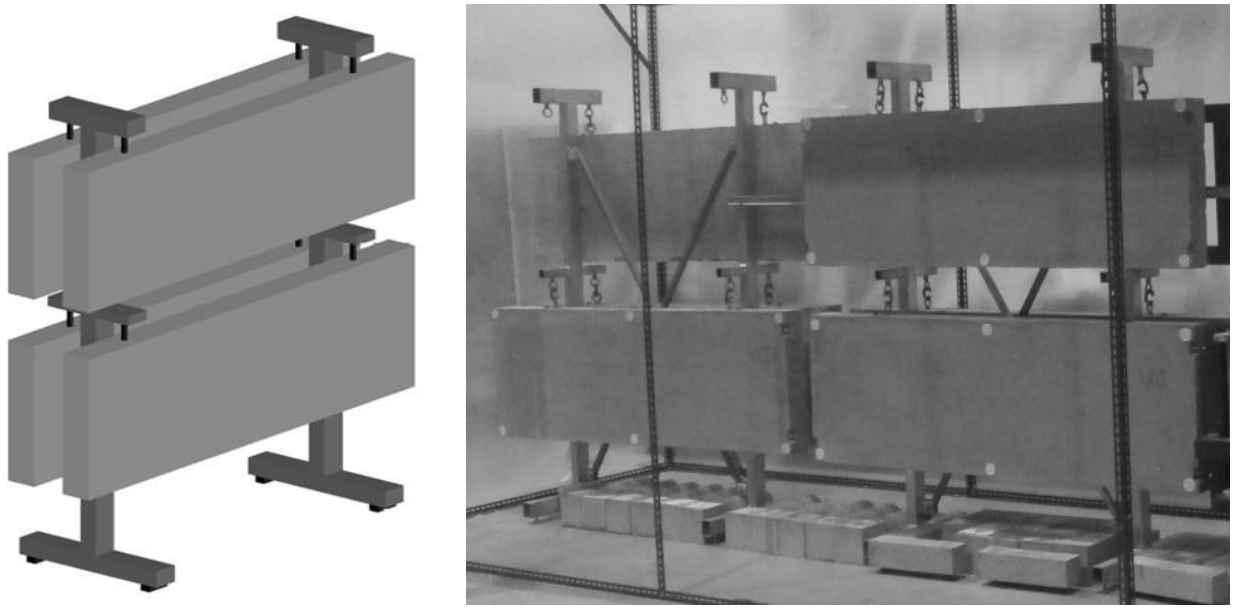

Fig. 1. Way of hanging the slabs.

For first test 4 unreinforced slabs were concreted and placed in an environment with a relative humidity of $R H=53 \%$. At time $t=28$ days from concreting, the cube strength of concrete was determined $f_{c \text {, cube }}=43.1 \mathrm{MPa}$, tensile strength of concrete at $f_{t}=2.23 \mathrm{MPa}$ and value of modulus of elasticity $E_{c}=34.34 \mathrm{GPa}$ [1].

For second test only one unreinforced slab was made (like a reference sample to reinforced slabs) and placed in an environment with a average relative humidity of $R H=$ $40 \%$. At time $t=28$ days from concreting, the cube strength of concrete was determined $f_{c, \text { cube }}=46 \mathrm{MPa}$, tensile strength of concrete at $f_{t}=4.23 \mathrm{MPa}$ and value of modulus of elasticity $E_{c}=30.7 \mathrm{GPa}$. Other slabs were reinforced by steel B500 (with modulus of elasticity $E_{s}=200 \mathrm{GPa}$ ), resp. GFRP reinforcement (with modulus of elasticity $E_{f}=55 \mathrm{GPa}$ resp. $50 \mathrm{GPa}$ ), with different reinforcing ratio in longitudinal direction $-0.3 \%, 0.5 \%$ and $0.8 \%$ (Fig.2) [2].

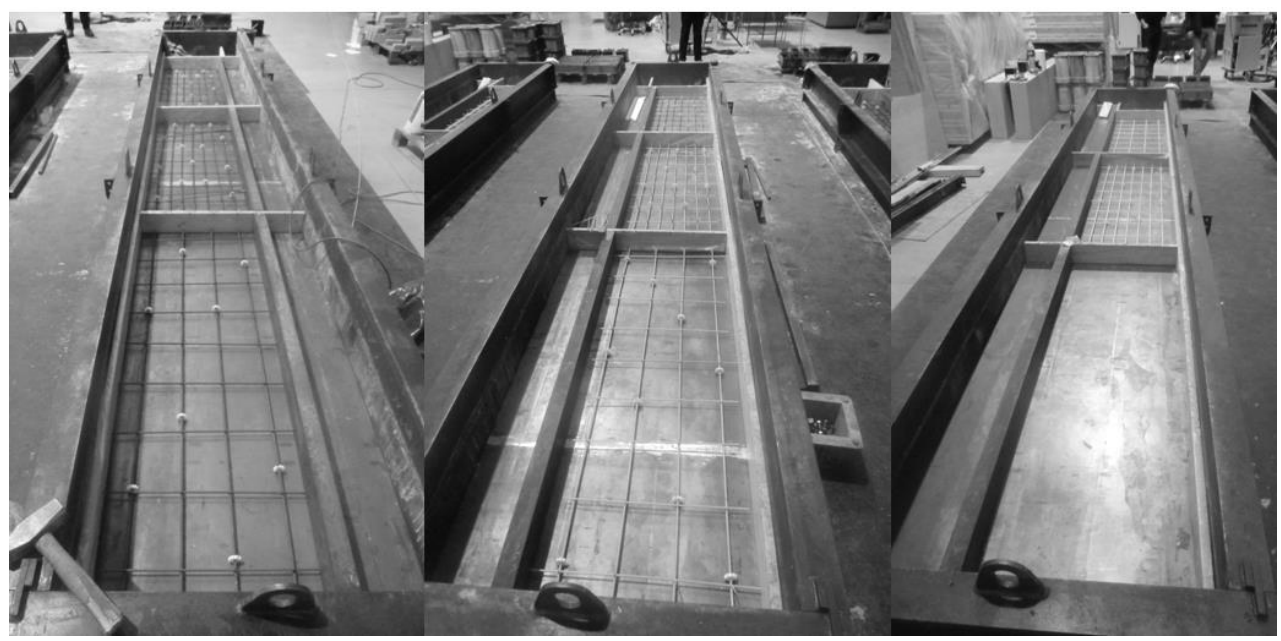

Fig. 2. Reinforcement of slabs for test 2 . 
Measuring of strains was carried out by the steel attachment frame equipped with mechanical strain gauges for direct measurement of the deflection and by glued targets which represented one end of the measuring bases monitored by the attachment deformer. The second end of the measuring base was on the two border surfaces of the concrete slabs (Fig. 3). The strains were defined on two surfaces of slab (lower "L" and upper "U" surface - according to the position during concreting) from average value of slab shortening measured by deformer on measuring bases (Z1-Z2 for "U" surface and Z3-Z4 for "L" surface). The strain in the centreline ("C") was determined from the linear course over the thick of slab. Similarly as strains, the deflection was calculated from measured displacement on " $U$ " surface (O1-O6).

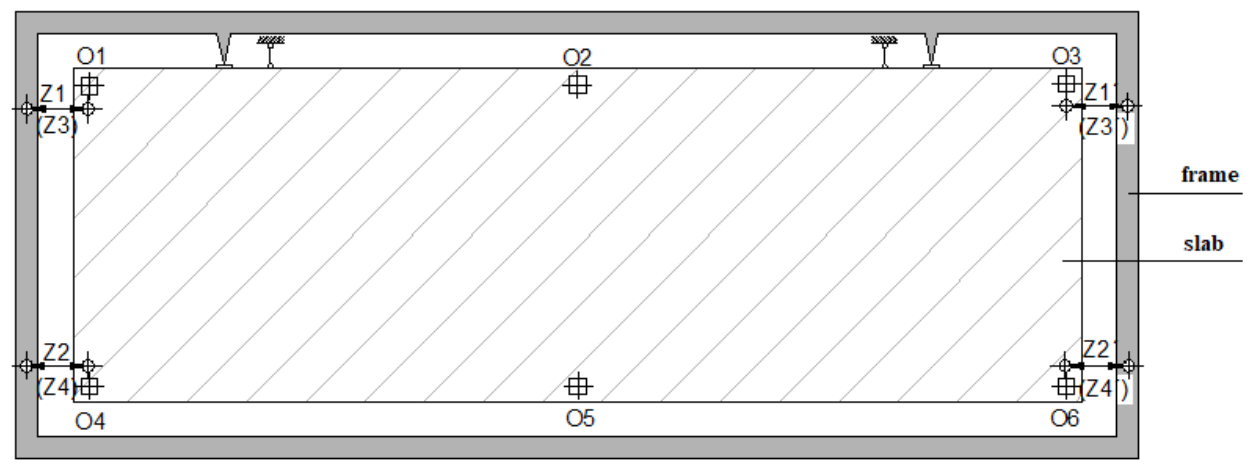

Fig. 3. Way of strain measuring by the steel attachment frame (Oi- mechanical strain gauges, Zimeasuring base for monitoring by the attachment deformer).

\section{Results}

It is known that any non-homogeneity of the material over the thickness of the slab causes uneven shortening of the fibres. In our case, the experimental program confirmed this significant effect of non-homogeneity of concrete on uneven shortening of fibres at both surfaces of the slab. This effect of the concrete non-homogeneity on the time evolution of the relative strains of the fibres at both surfaces of the unreinforced slabs is shown in Figure 4. The compacting was carried out by an immersion vibrator, what caused a certain stratification of the concrete at both surfaces of the plate and therefore a different shrinkage. In Figure 4, the thin dashed lines belonging to the group "U" represent the time evolution of the relative strains of the upper filaments and the thin dot-and-dashed lines in the group "L" represent the time evolution of the relative strains of the lower filaments. The group of thin solid lines " $\mathrm{C}$ " represents the time evolution of the relative strains of the centreline of the individual slabs from shrinkage. The thick solid lines represent calculated strains according to standard STN EN 1992 [3]. Lines without marks belong to test 1, with marks to test 2.

Results of measuring were compared with national standard calculation. The strains from shrinkage were calculated according to STN EN [3] as the sum of strains from drying shrinkage and autogenous shrinkage.

$$
\varepsilon_{c s}=\varepsilon_{c d}+\varepsilon_{c a}
$$

The value of $\varepsilon_{c, 0}$ was considered under Appendix B.2 [3] by more accurate calculation and then used for strain from drying shrinkage calculation.

$$
\varepsilon_{c d}=0,85 \beta_{d s}\left(t, t_{s}\right) k_{h}\left[\left(220+110 \alpha_{d s l}\right) \exp \left(-\alpha_{d s 2} f_{c m} / f_{c m 0}\right)\right] \cdot 10^{-6} \beta_{R H}
$$




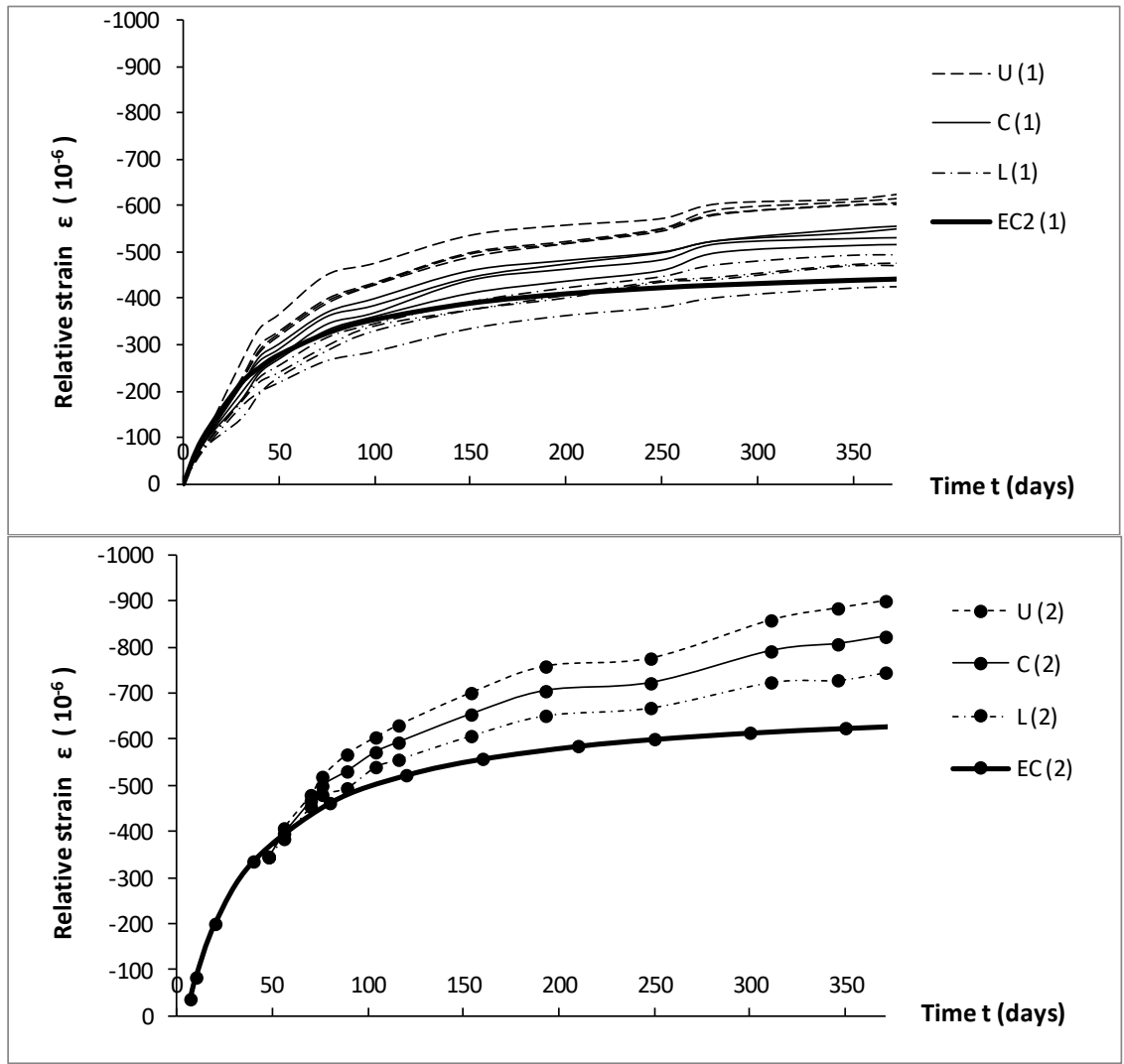

Fig. 4. Time evolution of the relative strains of the centreline and filaments at both surfaces of unreinforced samples caused by concrete shrinking (U- upper filaments, L- lower filaments, Ccentreline of slab, EC2 - calculation according to STN EN 1992 [3], (1)/(2) - number of test).

The final value of the shrinkage detected directly on the samples (as a strain of centreline of slab) is greater than that predicted in the standard regulations or recommendations. What can be seen from course of the curves on Figure 4. From our measurements, the real value of relative strain of shrinkage is $20 \%$ in test 1 and $29 \%$ in test 2 greater than the calculated value (in time 350 days).

The difference in shortening of upper and lower filaments from centreline of slabs in test 1 was $14 \%$, in test 2 was $10 \%$. These values clearly depend on properties of concrete and environment in which slabs were stored. Due to these differences, a deflection from shrinkage also occurs on the unreinforced slabs. The slab (from test 2) had deflection from shrinkage of value $0.45 \mathrm{~mm}$, which is $6.25 \%$ of limit value for ceiling constructions $(L / 250=7.2 \mathrm{~mm})$.

In the reinforced slabs can be value of deflection from shrinkage itself much higher (20\% - 30\% from limit value) according to reinforcing ratio and type of reinforcement (value of modulus of elasticity is significant). The partial results of measuring deflection caused by shrinkage on slabs reinforced by steel reinforcement are shown on Figure 5. Influence of concrete non-homogeneity represents $25 \%$ - $40 \%$ from total deflection caused by shrinkage of slabs reinforced by steel reinforcement. Especially for slabs with low 
reinforcing ratio, the effect of non-homogeneity is significant (40\%). Therefore, the effect of non-homogeneity for these elements should be appropriately accounted for in the deformation calculation when designing structures.

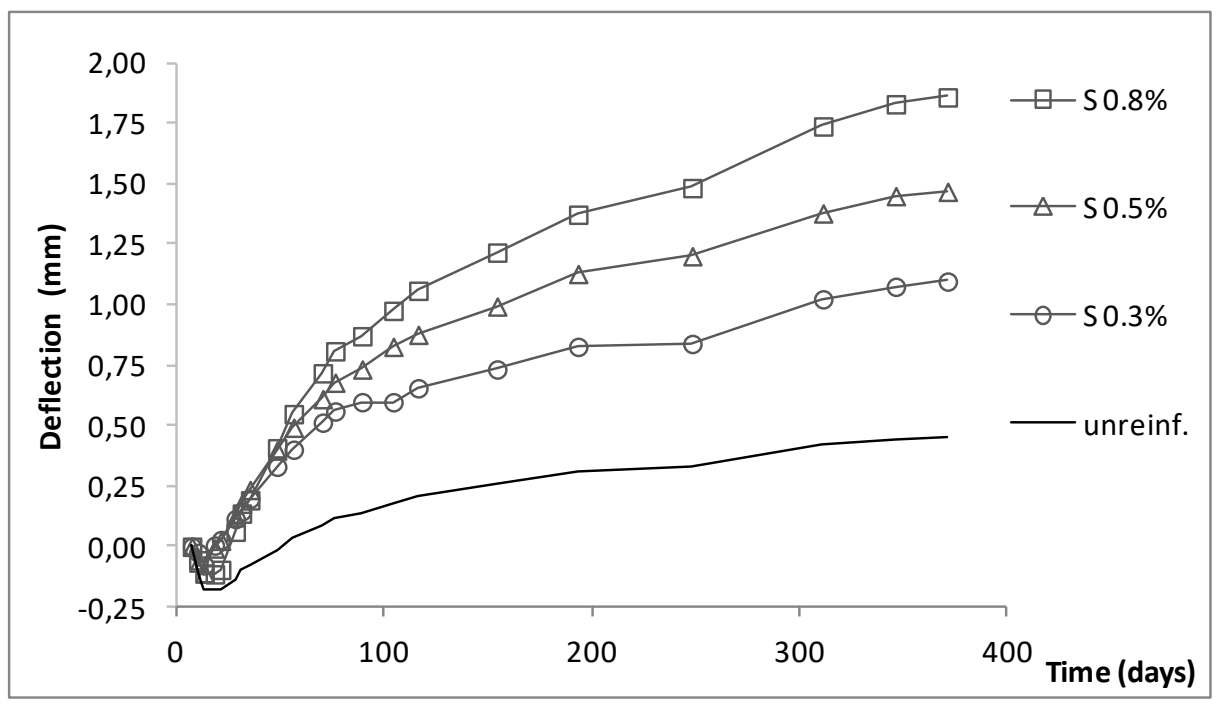

Fig. 5. Deflection of slabs reinforced by steel reinforcement and reference unreinforced slab.

\section{Conclusions}

The topicality of problem of stress and strain caused by concrete shrinking is now significant. With today's design philosophy of reinforced concrete elements, these forced strains caused by concrete shrinking are no longer negligible and must be considered in design and analysis of elements.

Attention must be paid to this effect, particularly in the case of long-term study of strains, especially in the case of flexibly less rigid elements, such as plates, where they can contribute significantly to the total value of the deformations. Their consideration is necessary to avoid possible misinterpretations of the results.

The article was supported by the scientific grant agency MŠVVaŠ SR and SAV by project VEGA 1/0661/16 Behaviour of load bearing elements from ordinary and light concrete affected by temperature.

\section{References}

1. D. Kušnírová, S. Priganc, Young Scientist 2018. (2018)

2. S. Priganc, D. Kušnírová, Š. Kušnír, Advances and Trends in Engieneering Sciences and Technologies III. CRC Press, 223-228 (2019)

3. STN EN 1992-1-1: Eurocode 2. Design of concrete structures. Part 1-1: General rules and rules for building construction. (2006) 